\title{
Towards a Micro-enterprise-focused Digital Maturity Framework
}

\author{
Olli Kuusisto, Jukka Kääriäinen \\ VTT Technical Research Centre of Finland Ltd, Finland \\ Kai Hänninen, Martti Saarela \\ University of Oulu, Finland
}

\section{ABSTRACT}

Digitalisation has been identified as one of the major trends changing society and business. However, companies are not making the most of all the opportunities that digitalisation has to offer. In the digital transformation process, it is important to start with assessing the current state. Digital maturity assessment can be used to analyse the current level of digital readiness and performance of an organisation.

Micro-enterprises are the smallest group of enterprises and numerically the dominant enterprise type in economies. They differ from larger enterprises in terms of organisational characteristics, such as their unique attitude towards digital tools and application deployment. Furthermore, micro-enterprises are lagging behind in exploring the possibilities that come with digitalisation.

This article describes the design process, usage possibilities and initial experiences of a digital maturity model especially from the viewpoint of micro-enterprises. As result, this article presents a microenterprise-focused self-evaluation framework providing holistic digital maturity status.

Keywords: Digital Maturity, Maturity Assessment, Digitalisation, Digital Transformation, Service Design, Micro-enterprise, Self-assessment

\section{INTRODUCTION}

Digitalisation has been identified as one of the major trends changing society and business (Tihinen \& Kääriäinen, 2016). Nevertheless, just 17\% of small to medium-sized enterprises (SMEs) in Europe are highly digitised (European Court of Auditors, 2019). Furthermore, the concept of digitalisation is multidimensional, often vaguely defined and dependent on the speaker's background. It is both about transforming the core business using digital tools and discovering and capturing new opportunities enabled by digitalisation (Furr \& Schipilov, 2019). Hence, digitalisation can mean enhancing existing processes, finding new opportunities within existing business domains or finding new opportunities outside existing business domains (Parviainen, Tihinen, Kääriäinen, \& Teppola, 2017).

Companies have also found it challenging that digitalisation affects so many aspects; besides information technology, it also affects the strategy and business model, products and services, internal and external processes, the organisational structure and the company culture, among other aspects (Leino, Kuusisto, Paasi, \& Tihinen, 2017). Therefore, a holistic conceptualisation of digitalisation is needed.

Digital transformation is a key enabler for maintaining competitiveness and reacting to continuous changes and pressure. Parviainen et al. (2017) define digital transformation as changes in the ways of working, in organisational roles and in business offerings, which are caused by the adoption of digital technologies in an organisation or in the operation environment of the organisation. The main issue is 
how companies can tackle digital transformation. For this purpose, companies should know their current state of digitalisation in order to determine their digitalisation improvement needs (Pham, 2010).

A micro-enterprise is a private enterprise employing fewer than 10 employees and having an annual turnover or balance sheet below $€ 2$ million (Commission of the European Communities, 2003). Microenterprises are the smallest group of SMEs in terms of size and numerically the dominant enterprise type in the economy (Saarela, Niinikoski, Muhos, Isoherranen, \& Leviäkangas, 2018); they represent almost 93\% of the enterprises in EU28 in 2015 (Muller et al., 2016). Micro-enterprises are different from larger SMEs because they are entrepreneur centred (Gherhes, Williams, Vorley, \& Vasconcelos, 2016); they are also intrinsically different in terms of their organisational characteristics and approach to business challenges and obstacles (Kelliher \& Henderson, 2006; O’Dwyer \&Ryan, 2000).

According to Jones, Simmons, Packham, Beynon-Davies and Pickernell (2011), the strongest inhibitors to adopting (e-business) digital services and applications are the time to develop a digital operation, limited information technology (IT) skills, low customer/supplier usage and insufficient financial resources. On the other hand, the strength of micro-companies is their agility, as they can be flexible in implementing projects and carrying out rapid openings (Saarela et al., 2018). The ability to adopt information and communication technologies (ICT) is related to the size of enterprises, and micro-enterprises evidently lag behind (Arendt, 2008). Moreover, the rate of technology adoption in micro-enterprises is highly dependent on the passion and interest that the owner-manager has for technology (Ritchie \& Brindley, 2005).

Maturity models can contribute to organisational transformation and the development of competencies in organisations by initiating a change process (Mettler, Rohner, \& Winter, 2010). Maturity models usually include a sequence of levels or stages which form a logical path from an initial state to a final level of maturity (Becker, Knackstedt, \& Pöppelbuß, 2009). These levels or stages are used to derive and prioritise improvement measures and control the progress of changes (Iversen, Nielsen, \& Norbjerg, 1999). Research has introduced several digital maturity models since the seminal work by Venkatraman (1994), and these models offer a good understanding of digital challenges and are useful when companies develop their digital transformation practices (Valdez-de-Leon, 2016). However, there is a lack of digital maturity models with wide scope focused especially on micro-enterprises. The aim of the present research was driven by the practical need for tools to support the digital transformation and development of microenterprises. The authors see that current models do not take into account the special characteristics of micro-enterprises, as even research does not distinguish micro-enterprises from SMEs (Falk et al., 2014; Kelliher \& Reinl, 2009). The model presented in this paper, which is a micro-enterprise-focused digital maturity framework, is intended to fill this gap.

In providing the framework, the authors use the guidelines of service design for the design and development of services (de Sousa Pereira \& da Silva, 2010; Mettler, 2010; Stickdorn, Hormess, Lawrence \& Schneider, 2018). In the service design approach, the aim is to create services that are useful, usable, desirable, efficient and effective (Holmlid \& Evenson, 2008).

\section{BACKGROUND}

Preparing for a digital future is not an easy task. It means developing digital capabilities in which an organisation's activities, people, culture and structure are in sync and aligned towards a set of organisational goals (Kiron, Kane, Palmer, Phillips, \& Buckley, 2016). As stated previously, Parviainen et al. (2017) define digital transformation as changes in the ways of working, in organisational roles and in business offerings, which are caused by the adoption of digital technologies in an organisation or in the operation environment of the organisation. This can refer to changes at the process, organisational and business levels. 
As digital transformation is often based on IT systems, its implementation is the most common means of changing the way work is done in organisations (Kuutti, 1999), which is the ultimate result of digital transformation. However, the transformation needs to be organisation-wide in order to reach the best results possible. According to Henriette, Mondher and Boughzala (2015), a digital transformation project involves implementing digital capabilities to support business model transformation affecting an entire organisation, especially its operational processes, resources and internal and external users. This is a major change in the habits and ways of working based on collaboration and intensive interactions.

Organisations cannot neglect digitalisation; instead, they need to think how to implement it in practice in order to best benefit from it within the organisation's own context. Parviainen et al. (2017) present a conceptual framework for digital transformation. This framework describes a systematic way of assessing the opportunities and threats related to digitalisation. This model makes a company more aware of the development of digitalisation and better prepared for the changes it requires in the organisation's own business operations. Therefore, it provides a model for supporting the organisation in its digitalisation pathway. The framework has the following four stages (Parviainen et al., 2017):

- Positioning: Involves analysing the potential impact of digitalisation on the company and deciding on the position that the company wants or needs to take in the change. Finding out the big picture-where we are and where we want to be.

- Current state analysis: Involves reviewing the current state of the company with respect to the desired position and impact of digitalisation, as well as identifying the gap between the current situation and the wanted future

- Roadmapping: Involves developing the measures to be taken in order to close the gap from the organisation's current state to the desired position, as well as planning the concrete actions needed to reach the desired position

- Implementation: Involves experimenting, implementing and validating the actions and returning to the previous steps, as needed

Figure 1. The four stages of digital transformation. Modified from Parviainen et al. (2017).

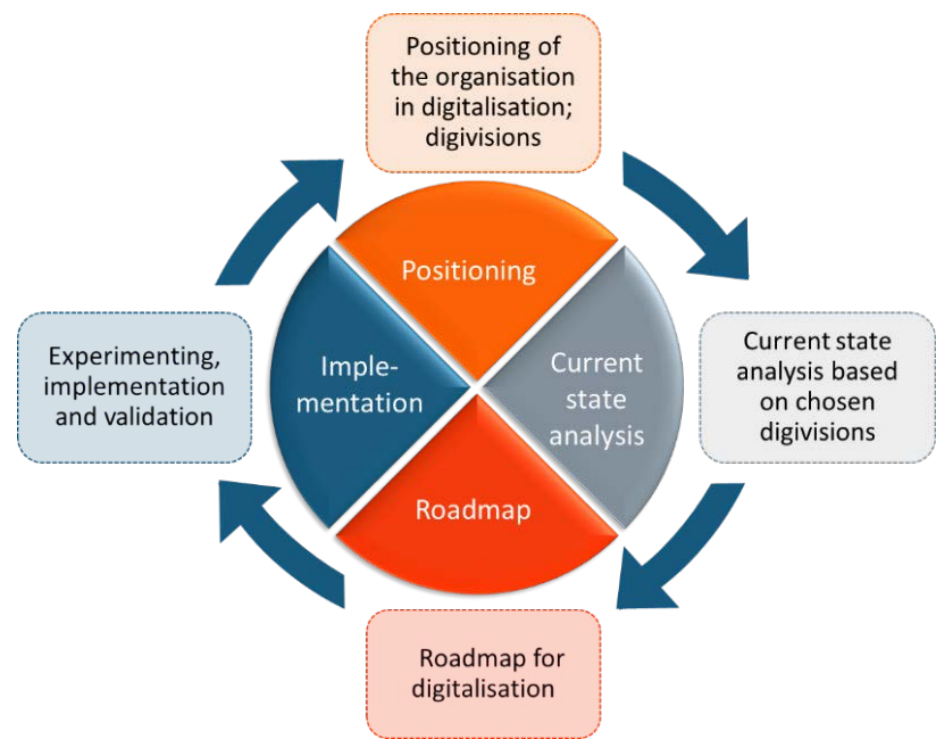

In order to improve digitalisation and enhance the digital transformation process in an organisation, one needs to understand the current digitalisation status of the organisation, i.e. digital maturity. Digital 
maturity assessment can be used to analyse the current level of digital readiness and performance of an organisation.

Maturity models have a long history, and many models developed for various purposes can be found in the literature. The use of maturity as a measure to evaluate the capabilities of an organisation with regard to a certain discipline or field of business has become popular since the capability maturity model (CMM) was proposed by the Software Engineering Institute (SEI) of Carnegie Mellon University and has been proven in practice (Paulk, Curtis, Chrissis, \& Weber, 1993; Wendler, 2012). The term 'maturity' relates to the degree of formality and optimisation of processes, from initial/ad hoc to optimising practices. The CMM's aim is to improve software development processes, but it can also be applied to other processes. The capability maturity model integration (CMMI) is the successor of the CMM and was developed by a group from the industry, government and the SEI at Carnegie Mellon University. CMMI models are collections of best practices that help organisations to improve their processes (Chrissis, Konrad, \& Shrum, 2011). CMMI models provide guidance for developing or improving processes that meet the business goals of an organisation.

Many of the maturity models base their levels on the CMMI's five-level evolutionary path of increasingly organised and systematically more mature stages. In addition to scientific maturity models, there are also a large number of maturity models developed by consultants, associations and initiatives, mostly having four to eight dimensions and five levels of maturity (e.g. Anderl et al., 2015; Felch, Asdecker, \& Sucky, 2019). Maturity models offer organisations a simple but effective tool to measure their capabilities (Leino et al., 2017; Wendler, 2012) and contribute to organisational transformation and the development of competencies in organisations by initiating a change process (Mettler, Rohner, \& Winter, 2010). Originating from software engineering, these models have expanded their application fields, and maturity model research is becoming increasingly important. According to Wendler (2012), maturity model research has been applied to more than 20 domains but is still heavily dominated by software development and software engineering (CMM, CMMI). Other prominent maturity model areas are product lifecycle management (PLM), business process management (BPM) and Industry 4.0 (e.g. Felch, Asdecker, \& Sucky, 2019; Silventoinen, Pels, Kärkkäinen, Lampela, \& Okkonen, 2013). Maturity models are especially suitable tools for (1) documenting the current state, (2) developing the future vision and providing guidance on that development path and (3) comparing the capabilities between organisations (Felch \& al., 2019; Leino et al., 2017).

Digital maturity is about enabling an organisation to adapt and thus compete effectively in an increasingly digital environment (Kane, Palmer, Nguyen Phillips, Kiron, \& Buckley, 2017). Maturity goes far beyond simply implementing new technology by aligning the company's strategy, workforce, culture, technology and structure to meet the expectations of customers, employees and partners. Kane et al. (2015) compare the differences between digitally early-stage, developing and maturing companies. They found that maturing companies typically have a clear digital strategy combined with a collaborative culture and leadership that drives the transformation. Hence, digital maturity is seen as result of strategy, culture and leadership combined.

The level of digitalisation and ICT adoption is related to the size of enterprises, and micro-enterprises are evidently lagging behind (Arendt, 2008). Micro-enterprises' focus is more on day-to-day issues to ensure survival (Faherty \& Stephens, 2016). They are laggards compared with larger enterprises, for example, in adopting e-business applications, as they make little use of e-business and have low website presence (Vlachos, 2011). The digital environment is changing rapidly, and for micro-enterprises, in particular, digital marketing is currently a vital opportunity for building customer relationships in from attracting customers to learning their preferences and relating to customers (Nikunen, Saarela, Oikarinen, Muhos, \& Isohella, 2017). It is widely acknowledged that micro-enterprises experience resource scarcity, which forces them to operate under financial and expertise constraints (Kelliher \& Reinl, 2009). Because of 
these size and resource issues, micro-enterprises are expected to have a unique attitude and strategic responses towards ICT adoption (Jones et al., 2014); however, the rate of technology adoption in microenterprises is highly dependent on the passion and interest that the owner-manager has for technology (Ritchie \& Brindley, 2005). Simmons, Armstrong and Durkin (2008) point out the role of the owner as having more significance in micro-enterprises than in larger counterparts. Decision making relies on the owner's intuition; thus, there is pressure on the owner-manager to be an expert in all fields of management, including the management of digital transformation (Kelliher \& Henderson, 2006). Development in micro-enterprises is a process of slow, incremental, iterative adaptation to emerging situations, rather than a sequence of clear steps or decision points (Perren, 1999). Micro-enterprises are more likely to adopt technology that they perceive to be of a close fit with their business model. Based on the above discussion, micro-enterprises cannot be considered and studied in the same manner as larger companies (Jones et al., 2014).

Drawing on relevant literature about digital maturity, gaining insights from direct observations and conversations in the field (see Creswell, 2009), i.e. with micro-entrepreneurs, business developers and entrepreneurship researchers, and utilising service design principles, the authors develop a microenterprise-focused digital maturity framework that can be used as a self-evaluation tool to support the digital transformation of micro-enterprises.

\section{DESIGNING A MICRO-ENTERPRISE-FOCUSED DIGITAL MATURITY MODEL}

Service design is a holistic, multidisciplinary and integrative field (Moritz, 2005). It provides guidance for the design and development of services (de Sousa Pereira \& da Silva, 2010). It consists of the design of the overall service experience, as well as the process and strategy of providing the service (Moritz, 2005). Unlike products, services exist only in interaction with customers who co-create the value of the service (Vargo \& Lusch, 2008). Therefore, the users of the services should be even more closely involved in the service development process.

Mettler (2010) has suggested a framework for design activities and decisions in the development of maturity models, and this has been taken as a general guideline in the development of the digital maturity model and in its fine-tuning for micro-enterprises. It includes following phases: (1) Identify need or new opportunity - is there a need for a new maturity model regarding both novelty of the topic and novelty of the content, (2) Define the scope, i.e. the breadth, depth and audience, (3) Design model, including where the focus is put (process, object, people, or combination), if the goal is one- or multidimensional, if the design is theory-driven, practitioner-based or combination, design product i.e. in what form the maturity model is published, application method i.e. if it can be used independently or if assistance is needed, and who is it meant for i.e. who would be the respondents, (4) Evaluate design, including testing both the process and end result (the model itself), if the point of time of the evaluation ex ante or ex post, having also effect on the evaluation method (e.g. simulation vs. case studies), and finally (5) Reflect evolution, or the positioning towards the evolution of the model, i.e. should it be changed at all and if yes would it include form or functioning or both, how often it should be reflected, if modifications can be done by users or only by the developers, and if the model will be freely available or not.

Stickdorn et al. (2018) have presented the following six principles of service design thinking which include partly same elements:

- Human centred: It considers the experience of all the people affected by the service

- Collaborative: Stakeholders of various backgrounds and functions should be actively engaged in the service design process.

- Iterative: Service design is an exploratory, adaptive and experimental approach, iterating towards implementation. 
- Sequential: The service should be visualised and orchestrated as a sequence of interrelated actions.

- Real: Needs should be researched in reality, ideas prototyped in reality and intangible values evidenced as physical or digital reality.

- Holistic: Services should sustainably address the needs of all stakeholders throughout the entire service and across the business.

Visualisations or models, prototyping and enactments are crucial to a successful service design (Holmlid \& Evenson, 2008). This is also one reason why the digital maturity framework and tool has been developed in phases, with the first involving the content with the questions and answer options in a document. Based on the feedback, the first version of the online tool was made, and then it was assessed again and redesigned based on the comments.

\section{Design of the Digital Maturity Model}

The research approach was constructive and iterative. In the first phase, concepts and models from the literature were studied and incorporated into six dimensions representing business, people, organisation and technology viewpoints (Leino et al., 2017). The dimensions are introduced in the following table (Table 1). The digital maturity model is a generic model designed so that it can be applied to any organisation. In practice, it has been found to be applicable to SME-sized organisations, in particular. The developed digital maturity model does not explore specific technologies but an organisation's operations in a comprehensive manner.

Table 1. Dimensions of the digital maturity model

\begin{tabular}{|l|l|}
\hline Dimension & Description \\
\hline Strategy & A strategy is an organisation's plan for pursuing its mission and achieving its objectives. \\
\hline Business model & $\begin{array}{l}\text { A business model is an architectural-level description of an organisation and its business } \\
\text { functions; it describes the value proposition, key customer segments and the ways to reach } \\
\text { customers and manage customer relationships, define the key functions and resources needed } \\
\text { to implement them, identify key partners, understand the cost structure and determine the } \\
\text { earnings logic. }\end{array}$ \\
\hline $\begin{array}{l}\text { Customer } \\
\text { interface }\end{array}$ & $\begin{array}{l}\text { A customer interface refers to those activities involving customers, such as marketing, sales, } \\
\text { delivery and customer service. }\end{array}$ \\
\hline $\begin{array}{l}\text { Organisation } \\
\text { and processes }\end{array}$ & $\begin{array}{l}\text { The traditional structure diagram of an organisation describes the tasks of the members of the } \\
\text { organisation, the division of labour and the reporting relationships. Processes consist of a } \\
\text { series of operations related to one another or that are interactive. Each operation involves } \\
\text { tasks, roles, responsibilities, timelines and deliverables. In digitalisation, processes are } \\
\text { primarily concerned with the processing of information and data in digital form. }\end{array}$ \\
\hline $\begin{array}{l}\text { People and } \\
\text { culture }\end{array}$ & $\begin{array}{l}\text { The term 'people' refers to human resources; people are understood as either an individual or } \\
\text { a group, and they affect the performance of the organisation. Culture refers to the importance } \\
\text { of attitude and behaviour in an organisation's performance. }\end{array}$ \\
\hline $\begin{array}{l}\text { Information } \\
\text { technology }\end{array}$ & $\begin{array}{l}\text { Information technology broadly refers to digital editing, transmission, } \\
\text { storage, searching and presentation of data or information. IT covers the use } \\
\text { of any computers, storage, networking and other physical devices, as well as infrastructure and } \\
\text { processes to create, process, store, secure and exchange all } \\
\text { forms of digital data. }\end{array}$ \\
\hline
\end{tabular}

In the second phase, the maturity levels for each dimension were defined and described. Then, the initial evaluation of the developed model was done iteratively. It was first presented and discussed internally in workshops, and after a few modifications, it was introduced to a selection of organisations in order to obtain external feedback before the implementation of a public web tool. 
Each dimension of the maturity model included four to five questions that measure the status of an organisation in terms of digitalisation. Mostly, it meant having one basic question on the dimension, whereas the rest focused more on digitalisation aspects. The self-assessment is done by selecting the most suitable option from the alternatives for each question. The digital maturity value of each dimension is calculated as the average value of the questions in that dimension. Thus, the result describes the organisation's digital profile based on the answers, giving a baseline for development actions.

Furthermore, it helps in understanding and structuring the ambiguous concept of digitalisation, which has been found to be useful when starting digitalisation projects. This relates particularly to achieving a common understanding of digitalisation and the current maturity level in an organisation.

Digimaturity is assessed using a scale from 0 to 4 . The lowest score means that digitalisation has not yet been utilised, whereas the highest score means that the organisation both applies digitalisation and follows and develops it. The objective is not to reach the highest level of maturity in every dimension, but it is important for companies to be aware of their current status and consider the level they should aim for.

\section{Design of the Digital Maturity Self-assessment Tool}

The public web tool was developed as a self-assessment tool for all organisations. It was created for directors, managers and experts to understand the concept of digitalisation and assess their current digital maturity level. It can be used as a free-of-charge online self-assessment tool that gives the baseline of the current digital maturity level in six dimensions, which can be used for recognising the most important development targets depending on the nature of the organisation's business and its position in the value network. Second, it helps in understanding and structuring the ambiguous concept of digitalisation. Third, it can be used for collecting different views on digital maturity if people from different functions and organisational levels fill out the questionnaire. Fourth, it can be used to compare and benchmark the current state of digitalisation and development in own organisation; it can be used for comparison purposes with different organisations in the same domain, size, location and so on when there are enough respondents.

After replying to the tool's questions, the respondents get a diagram of the current state of the six dimensions of the model (Figure 2). The result diagram shows the values of their own organisation and the reference values of all respondents. More specific comparisons based on the branch or size of the organisation can be made if there are enough respondents in the reference group. 
Figure 2. Result diagram of the digital maturity web tool. The diagram shows the digital maturity of the organisation and the reference values of all organisations. The reference group data can be retrieved if there are enough answers in the reference group.
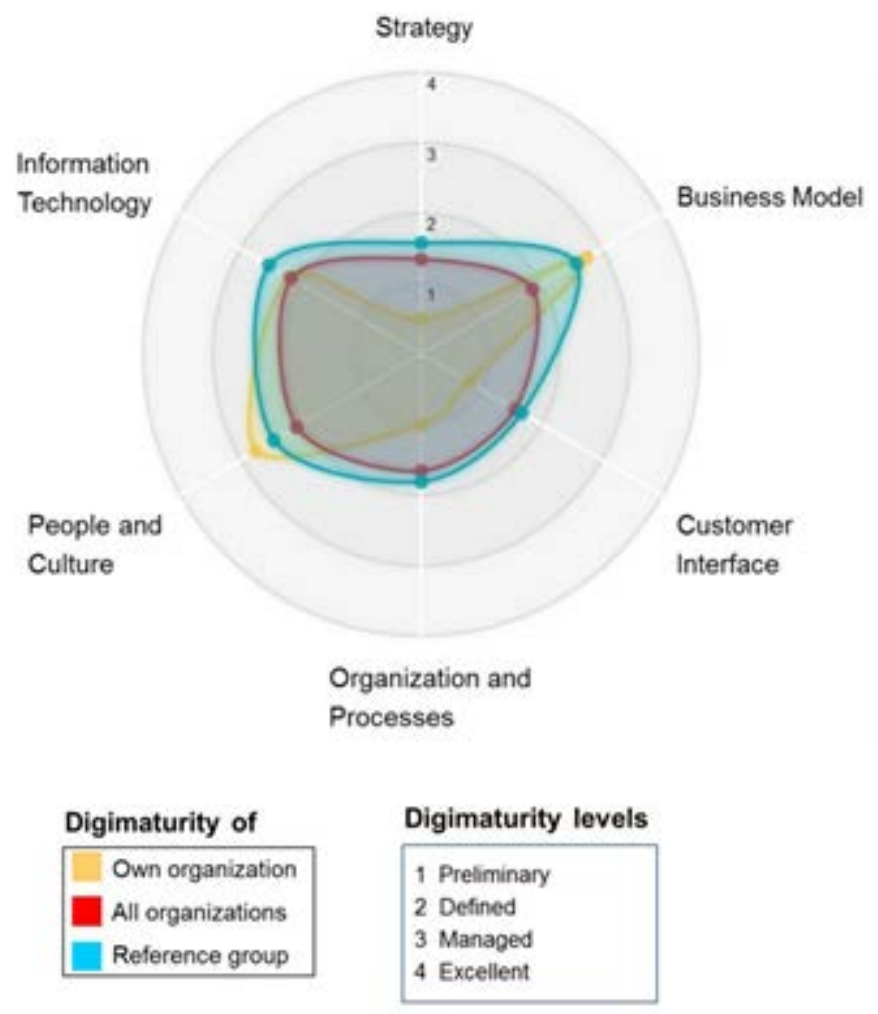

The results give justified grounds for considering a suitable target level for one's own organisation in various dimensions, as well as different measures for reaching the desired level. This will help an organisation create the best possible digitalisation strategy taking into account the entire organisation, as well as target the necessary development steps in accordance with the strategy for the most beneficial outcomes.

As the tool was meant to be used as a self-assessment tool, there was a need to make it understandable enough to be used without any help. Therefore, after internal discussions in the researchers' organisations and external discussions with the selected organisations, the questions and response options of the tool were modified. Some questions were removed, as they were either too domain specific or would have required additional clarification in order to be understandable or just went too deep into the subject. The questions were aimed to be in between very brief/superficial and extensive/exhaustive. With a short inquiry, one often cannot get a good overall picture of the subject; with more extensive queries, one can obtain more information, but the scope may be lost with the size of it. The digital maturity tool is meant for the holistic evaluation of the digitalisation situation, and more focused questions are needed when going deeper into some of the dimensions.

At the moment, there are over 300 responses in the digital maturity database, of which about $60 \%$ come from companies. The share of micro-enterprises is about $30 \%$ of the companies. 


\section{Design of the Micro-enterprise-focused Self-assessment Maturity Tool}

The authors utilised previously mentioned service design principles when modeling a new customer category, micro-enterprises, and designing, prototyping and testing digital maturity framework. From the perspective of service design, understanding the role of users' expectations is vital (Zeithaml, Parasuraman, \& Berry, 1990). In order to respond to this, the authors have sought to understand and listen to the expectations of micro-enterprises regarding the framework.

The key element of designing services is that they are meant to engage customers (Pine \& Gilmore, 1999). The digital maturity framework and the related tool are designed to benefit and engage microentrepreneurs with the information that the user accumulates both from the concept and the current baseline of digital maturity. The desired engagement is based on rationality and pragmatism, as it is known that micro-enterprises require the framework to be easy to use and valuable in terms of digital and business development.

Micro-enterprises, including both entrepreneurs and their staff, and other stakeholders, such as support organisations, have participated in the service design process. The process itself has been iterative and tested with companies and supporting organisations, starting from the co-creation of the initial digital maturity model exploiting both the literature and practical experiences, as stated previously, up to the fine-tuning of the micro-enterprise-focused version. The service itself is compact; it consists of registration, the information input and a graph of the results. The main aim has been to illustrate the holistic concept of digitalisation and digital maturity and to determine the current state of digitalisation.

The initial digital maturity tool has been used to map the digitalisation status of companies in many projects and assignments. For example, in a project to be defined, it was used for current state analysis of 19 SMEs, based on which the companies have been able to identify their digitalisation targets. Seven companies represented small micro-enterprises or entrepreneurs. The companies answered the digital maturity tool, and then the researchers interviewed the company representatives about digitalisation in more detail. According to their experiences, the companies considered the mapping of their digitalisation status a good way of assessing where they are at present and in which direction they should steer their development measures next. However, when discussing and going through the results with the microenterprises and entrepreneurs, they commented that there are development needs regarding 1) the vocabulary/terms used, 2) how the questions and response alternatives are posed and the 3) need for concrete examples. On the other hand, the digitalisation interviews showed that some company representatives were more advanced in digitalisation than others were, so they understood the terminology better. This resulted from their education or personal interest about digitalisation.

The experts of the Federation of Finnish Enterprises expressed that even if the fields, operational environment and operations of the micro-enterprises and entrepreneurs differ significantly, the basic issues (i.e. the dimensions of the Digimaturity tool) remain the same. However, strategy and the business model, for instance, can be understood as almost one and the same by the micro-enterprises. Furthermore, the digital maturity framework is especially relevant for micro-enterprises seeking growth, as it includes the issues to be taken into account when the number of employees grows, such as communication and process definitions. Growth and digitalisation are closely connected especially with servitisation, in which digital services can be scaled up very fast when needed.

The feedback of the micro-enterprises and entrepreneurs, as well as that of the Federation of Finnish Enterprises, was analysed. The authors then revised the suggested self-assessment framework based on this feedback. Micro-enterprise-focused modifications of the new version of the digital maturity tool were made as follows: 
- Rephrasing some of the dimensions (e.g. Strategy $\rightarrow$ Development of operations, Organisation and processes $\rightarrow$ Ways of working, Organisation $\rightarrow$ company)

- Expanding and/or clarifying the definitions (e.g. IT architecture $\rightarrow$ Entity forming different information systems in the company, IT roadmap $\rightarrow$ IT development plan)

\section{- Rephrasing the questions and response options}

Figure 3. The micro-enterprise-focused digital maturity model's dimensions and categories (questions).
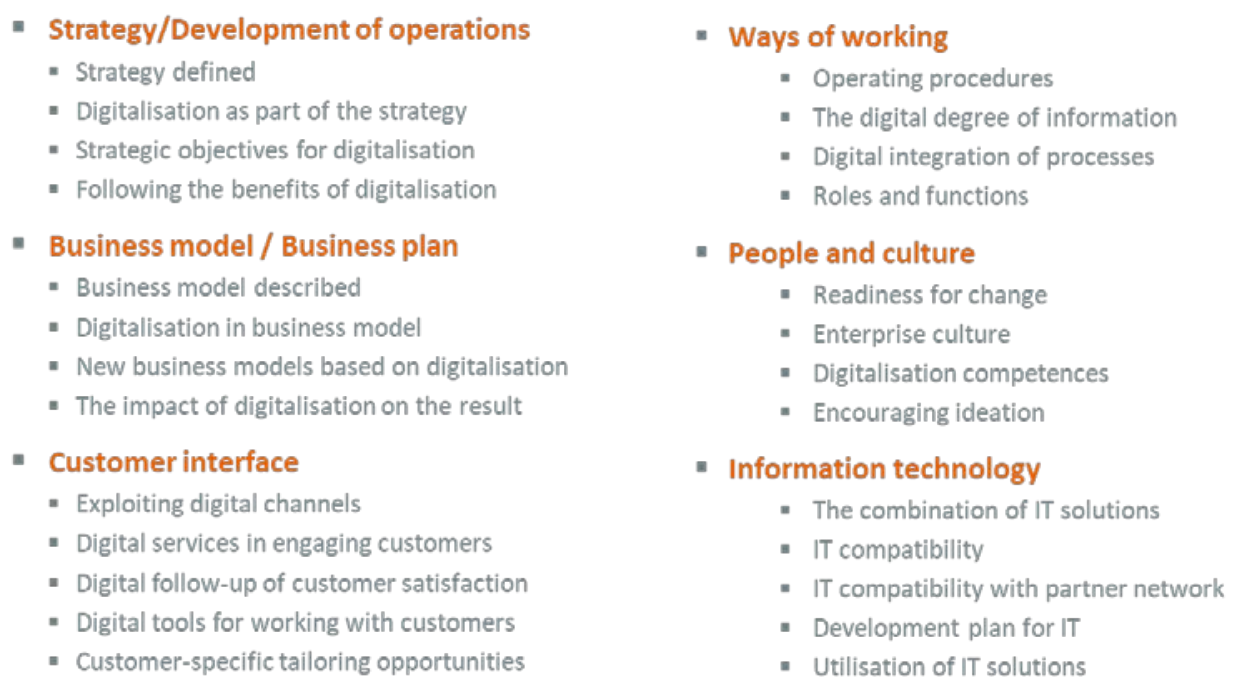

\section{CONCLUSION}

This article presents the development of a micro-enterprise-focused digital maturity self-evaluation framework and related tool providing a view of the overall status of digitalisation in a company. The process has been constructive and iterative, taking into account the users and their needs from the beginning. The resulting micro-enterprise-focused self-assessment tool of digital maturity has been constructed based on the comments to the more general tool.

This article covers the development and observations of a more general maturity model and the related tool for all organisations and the fine-tuning of these for micro-enterprises as a part of the digital transformation framework using service design principles.

The constructed digital maturity model can be used for conceptualising viewpoints on digitalisation, documenting the current state of digitalisation, setting the baseline for the future vision and providing guidance on the development path. The developed tool also offers possibilities for comparing capabilities between companies, as well as comparing within a company.

The basic objective in developing the digital maturity model and especially the related self-assessment tool has been to use service design principles so that the content, usability and usefulness of the model and the tool will benefit users in their quest for digital transformation. As stated previously, the construction of a digital maturity model in the first phase was based on organisations' need to understand the concept of digitalisation and to possess the capabilities to assess their current digitalisation state on a holistic level. In the second phase, after feedback from the micro-enterprises and stakeholders in the area has been obtained, the model and related tool have been fine-tuned to their needs. 
In developing the service design of the framework and the related tool, the following steps have been taken: a) investigating users' needs based on the literature and on practical experiences with implemented projects, b) setting such needs as the objectives in building the digital maturity framework and c) testing the model with selected companies in two phases, in addition to discussions with stakeholders.

The maturity framework and tool have been designed so that they fulfil the service design criteria of being useful, usable, efficient, effective and desirable. The initial users have stated that the tool gives a holistic view of digitalisation and a good overview of the current digital maturity level, as well as reveals opportunities for improvement.

In relation to the digital transformation framework by Parviainen et al. (2017), digital maturity assessment can be used in the positioning and current state analysis phases; it can also be used as a key performance indicator in the implementation phase. The goal is to integrate the tool into existing support services. For example, a to-be-defined project has created a web service that collects tools, methods and experiences in one place to support the digital transformation of SME companies. The initial digital maturity tool is one of these tools. In the future, a micro-enterprise-focused maturity tool version will be integrated into this service to better serve SME companies of different sizes.

The micro-enterprise-focused framework and tool have been implemented based on the initial feedback and needs of micro-enterprises and selected parties offering development support for micro-enterprises. Further research related to the applicability of this micro-enterprise-focused maturity framework and tool is needed. The next step will be to test the new framework with micro-enterprises and entrepreneurs. Based on the results, the framework needs to be modified, and the first version of the micro-enterprisefocused maturity tool will be created and further tested.

\section{ACKNOWLEDGMENT}

This publication has been supported by the "SoloENTRE ja Yrittävä kulttuuri” project which received funding from the European Regional Development Fund under grant agreement No A74362, and by the "DigiLeap" project which received funding from the European Regional Development Fund under grant agreement No A73467.

\section{REFERENCES}

Anderl, R., Picard, A., Wang, Y., Fleischer, J., Dosch, S., Klee, B., \& Bauer, J. (2015). Guideline Industrie 4.0-Guiding principles for the implementation of Industrie 4.0 in small and medium sized businesses. In VDMA Forum Industrie (Vol. 4).

Arendt, L. (2008). Barriers to ICT adoption in SMEs: How to bridge the digital divide? Journal of Systems and Information Technology, 10(2), 93-108.

Becker, J., Knackstedt, R. and Pöppelbuß, J. (2009), "Developing Maturity Models for IT Management - A Procedure Model and its Application". Business \& Information Systems Engineering (BISE), Vol. 1, No. 3, 213-222

Chrissis, M. B., Konrad, M., \& Shrum, S. (2011). CMMI for development: guidelines for process integration and product improvement. Pearson Education. 
Commission of the European Communities. (2003). Commission recommendation of 6 May 2003 concerning the definition of micro, small and medium-sized enterprises. Official Journal of the European Union, pp. L 124/36-41.

Creswell, J. (2009). Research design: Qualitative, quantitative, and mixed methods approaches (3rd ed.). Thousand Oaks, CA: Sage Publications.

de Sousa, Pereira, R. F., \& da Silva, M. M. (2010). A maturity model for implementing ITIL v3. Paper presented at the 2010 6th World Congress on Services, Helsinki.

European Court of Auditors. (2019). Audit preview: Digitising European industry. European Union. 12 pages. https://www.eca.europa.eu/Lists/ECADocuments/AP19_13/AP_digitising_industry_EN. pdf (accessed 20.9.2019)

Faherty, U., \& Stephens, S. (2016). Innovation in micro-enterprises: Reality or fiction? Journal of Small Business and Enterprise Development, 23(2), 349-362.

Falk, M., Murphy, G., Siedschlag, I., Hagsten, E., Sass, M., Szalavets, A., ... Mirza, D. (2014). Drivers of SME internationalisation: Implications for firm growth and competitiveness. Background study for the European Competitiveness Report 2014. Luxembourg: European Commission.

Felch, V., Asdecker, B., \& Sucky, E. (2019). Maturity models in the age of Industry 4.0 - Do the available models correspond to the needs of business practice? In Proceedings of the 52nd Hawaii International Conference on System Sciences. Hawaii International Conference on System Sciences. https://doi.org/10.24251/hicss.2019.620

Furr, N., \& Shipilov, A. (2019). Digital doesn't have to be disruptive. Harvard Business Review, 97(4), 94-103.

Gherhes, C., Williams, N., Vorley, T., \& Vasconcelos, A.-C. (2016). Distinguishing microbusinesses from SMEs: A systematic review of growth constraints. Journal of Small Business and Enterprise Development, 23(4), 939-963.

Henriette, E, Mondher, F., \& Boughzala, I. (2015). The shape of digital transformation: A systematic literature review. Paper presented at the Ninth Mediterranean Conference on Information Systems (MCIS), Samos, Greece.

Holmlid, S., \& Evenson, S. (2008). Bringing service design to service sciences, management and engineering. In B. Hefley, \& W. Murphy (Ed.), Service science, management and engineering education for the 21st century (pp. 341-345). Boston, MA: Springer.

Iversen, J., Nielsen, P. A. and Norbjerg, J. (1999), "Situated assessment of problems in software development". Database for Advances in Information Systems, Vol. 30, No. 2, 66-81. 
Jones, P., Packham, G., Beynon-Davies, P., \& Pickernell, D. (2011). False promises: e-business deployment in Wales' SME community. Journal of Systems and Information Technology, 13(2), 163-178.

Jones, P., Simmons, G., Packham, G., Beynon-Davies, P., \& Pickernell, D. (2014). An exploration of the attitudes and strategic responses of sole proprietor micro-enterprises in adopting information and communication technology. International Small Business Journal, 32, 285-306.

Kane, G. C., Palmer, D., Phillips, A. N., Kiron, D., \& Buckley, N. (2015). Strategy, not technology, drives digital transformation. MIT Sloan Management Review and Deloitte University Press, 14(1-25).

Kane, G. C., Palmer, D., Nguyen-Phillips, A., Kiron, D., \& Buckley, N. (2017). Achieving digital maturity. MIT Sloan Management Review, 59(1).

Kelliher, F., \& Henderson, J. B. (2006). A learning framework for the small business environment. Journal of European Industrial Training, 30(7), 512-528.

Kelliher, F., \& Reinl, L. (2009). A resource-based view of micro-firm management practice. Journal of Small Business and Enterprise Development, 16(3), 521-532.

Kiron, D., Kane, G. C., Palmer, D., Phillips, A. N., \& Buckley, N. (2016). Aligning the organization for its digital future. MIT Sloan Management Review, 58(1).

Kuutti, K. (1999). Activity theory, transformation of work, and information systems design. In Y. Engeström, R. Miettinen, \& R.-L. Punamäki (Eds.), Perspectives on activity theory (pp. 360-376). Cambridge, UK: Cambridge University Press.

Leino, S.-P., Kuusisto, O., Paasi, J., \& Tihinen, M. (2017). VTT model of digimaturity. In J. Paasi (Ed.), Towards a new era in manufacturing. Final report of VTT’s For Industry spearhead programme (pp. 41-46), Espoo, Finland: VTT. http://www.vtt.fi/inf/pdf/technology/2017/T288.pdf

Mettler, T. (2010). Thinking in terms of design decisions when developing maturity models. International Journal of Strategic Decision Sciences (IJSDS), 1(4), 76-87.

Mettler, T., Rohner, P., \& Winter, R. (2010). Towards a classification of maturity models in information systems. In A. D'Atri, M. De Marco, A.M. Braccini, \& F. Cabiddu (Ed.), Management of the interconnected world (pp. 333-340). Heidelberg: Physica-Verlag HD.

Moritz, S. (2005). Service Design: Practical Access to an Evolving Field. Cologne, Germany: Köln International School of Design

Muller, Patrice \& Devnani, Shaan \& Julius, Jenna \& Gagliardi, Dimitri \& Marzocchi, Chiara \& Hope, Editor. (2016). ANNUAL REPORT ON EUROPEAN SMEs 2015/2016 SME recovery continues. 10.13140/RG.2.2.12607.10405. 
Nikunen, T., Saarela, M., Oikarinen, E. L., Muhos, M., \& Isohella, L. (2017). Micro-enterprise’s digital marketing tools for building customer relationships. Management, 12(2), 171-178.

Parviainen, P., Tihinen, M., Kääriäinen, J., \& Teppola, S. (2017). Tackling the digitalization challenge: How to benefit from digitalization in practice. International Journal of Information Systems and Project Management, 5(1), 63-77. 2017. https://doi.org/10.12821/ijispm050104

O'Dwyer, M., \& Ryan, E. (2000). Management development issues for owners/managers of micro-enterprises. Journal of European Industrial Training, 24(6), 345-353. doi:10.1108/03090590010373334

Paulk, M. C., Curtis, B., Chrissis, M. B., \& Weber, C. V. (1993). Capability maturity model, version 1.1. IEEE Software, 10(4), 18-27.

Perren, L. (1999). Factors in the growth of micro-enterprises (Part 1): Developing a framework. Journal of Small Business and Enterprise Development, 6(4), 366-38.

Pham, Q. T. (2010). Measuring the ICT maturity of SMEs. Journal of Knowledge Management Practice, 11(1), 1-14.

Pine, B. J., \& Gilmore, J. H. (1999). The experience economy: Work is theatre and every business a stage. Boston, MA: Harvard Business School Press.

Ritchie, B., \& Brindley, C. (2005). ICT adoption by SMEs: Implications for relationships and management. New Technology, Work \& Employment, 20(3), 205-217.

Saarela, M., Niinikoski, E-R., Muhos, M., Isoherranen, V., \& Leviäkangas, P. (2018). Small- and medium-sized enterprises in public procurement in primary social and healthcare services. International Journal of Procurement Management, 11(1), 76-95.

Silventoinen, A., Pels, H. J., Kärkkäinen, H., Lampela, H., \& Okkonen, J. (2010). PLM maturity assessment as a tool for PLM implementation process. Paper presented at the PLM10 Conference, Bremen, Germany.

Stickdorn, M., Hormess, M. E., Lawrence, A., \& Schneider, J. (2018). This is service design doing: Applying service design thinking in the real world. Sebastobol: O'Reilly Media.

Tihinen, M., \& Kääriäinen, J. (Eds.). (2016). The Industrial Internet in Finland: On route to success? Espoo, Finland: VTT, VTT Technology. http://www.vtt.fi/inf/pdf/technology/2016/T278.pdf, 2016.

Valdez-de-Leon, O. (2016). A digital maturity model for telecommunications service providers. Technology Innovation Management Review, 6(8), 19-32.

Vargo, S. L., \& Lusch, R. F. (2008). Service dominant logic: Continuing the evolution. Journal of the Academy of Marketing Science, 36(1), 1-10. 
Venkatraman, N. (1994). IT-enabled business transformation: From automation to business scope redefinition. Sloan Management Review, 35(2), 73-87.

Vlachos, I. P. (2011). SMEs e-business behavior: A demographics and strategic analysis. Journal of Enterprise Resource Planning Studies, 2011, 1-21.

Wendler, R. (2012). The maturity of maturity model research: A systematic mapping study. Information and Software Technology, 54(12), 1317-1339.

Zeithaml, V. A., Parasuraman, A., \& Berry, L. L. (1990). Delivering service quality: Balancing customer perceptions and expectations. New York: The Free Press. 